\title{
Kinetic retention of sialic acid and antioxidants in Malaysian edible bird's nest during low-temperature drying
}

\begin{abstract}
Drying is one of the essential processing steps for dried edible birdôs nest; however, sialic acid and antioxidant can be highly thermosensitive and unstable. Therefore, aim of this study was to determine the degradation kinetics of sialic acid and antioxidants during lowtemperature drying at $25 \mathrm{i} 40^{\circ} \mathrm{C}$ as compared to conventional hot air-drying at $70^{\circ} \mathrm{C}$. These compoundsôdegradation exhibited first-order kinetics. Sialic acid and antioxidant retentions were 83.9 and $96.6 \%$, respectively, at $25^{\circ} \mathrm{C}$, and 78.7 and $91.5 \%$ at $40^{\circ} \mathrm{C}$, respectively, by low-temperature drying; while, 42.5 and $38.7 \%$, respectively, at $70^{\circ} \mathrm{C}$ by conventional hot air-drying. Finally, empirical models were significantly fitted to predict sialic acid and antioxidant retention as edible birdôs nest reached a certain level of drying, which may be useful from the processing standpoint and validate the usage of low-temperature drying as a process tool for retention of sialic acid and antioxidant in edible birdôs nest.
\end{abstract}

Keyword: Antioxidant; Edible bird's nest; Kinetic degradation; Low-temperature drying; Sialic acid 